\title{
Measurement of adsorption of a single component from the liquid phase: modelling investigation and sensitivity analysis
}

\author{
M.J. Heslop $^{1}$, C. J. Schaschke ${ }^{1}$, J. Sefcik ${ }^{1}$, D.J. Richardson ${ }^{2}$ and P.A. Russell ${ }^{3}$ \\ ${ }^{1}$ Department of Chemical and Process Engineering, University of Strathclyde, James Weir \\ Building, 75 Montrose Street, Glasgow, G1 1XJ, United Kingdom; email: \\ mark.heslop@strath.ac.uk; ${ }^{2}$ Department of Chemical Engineering, Loughborough University, \\ Ashby Road, Loughborough, Leicestershire LE11 3TU, United Kingdom; Department of \\ Chemical Engineering, University of Teesside, Middlesbrough, TS1 3BA, United Kingdom.
}

Keywords: $\quad$ adsorption, ethanol, liquid, flow measurement, theory

\begin{abstract}
In this work, we consider an alternative approach for the measurement of adsorption from the liquid phase. Consider a mixture consisting of a non-adsorbed component (B) and an adsorbed component (A) present at some low concentration. Initially, a feed of component B only flows through a column packed with an adsorbent. Then, the feed is switched to the mixture of A and B. As soon as the mixture enters the column, there will be a reduction in the outlet flow rate as component A leaves the liquid phase and passes into the adsorbed phase. There are three stages to this work. The first is to develop overall and component balances to show how the amount adsorbed of component A can be determined from the variation in the column outlet flow rate. The second is to determine the actual variation in the column outlet flow rate for both plug flow and axial-dispersed plug flow. The final stage is to consider the suitability of a gravity-fed system to deliver the feed to the column. An analysis of the results shows that the experimental arrangement should be able to accurately monitor adsorption from the liquid phase where the mass fraction of the solute is of the order of $1 \%$ : the limiting experimental factor is how constant the volumetric flow rate of the liquid feed can be maintained.
\end{abstract}




\section{Introduction}

In recent years, there has been an increase in the number of applications, publications and patents for adsorption in the liquid phase. This is in part due to the increasing number of purification applications, where the requirement is to remove a low concentration of a component which is capable of adsorption. One application is the removal of water from organic solvents. Lau et al. (2004) used a packed column of spherical beads of 3A zeolite to dry an ethanol solution containing $3.2 \%$ of water. The authors used titration to determine the concentration of water in ethanol and concluded that the application of oscillatory flow resulted in improved column performance. Environmental applications include the removal of phenol from water (Roostaei and Tezel, 2004) and naphthalene from water (Chang et al., 2004). In the former, the starting solution was phenol in water at a concentration of $200 \mathrm{ppm}$.

For the design of such purification and separation processes, a key parameter is the adsorption isotherm for a particular solute and material. This is conveniently written as

$q=f(c)$

where $q$ is the adsorbed-phase concentration (for which convenient units are say $\mathrm{mg} / \mathrm{g}$ ) and $c$ is the concentration of the solute in the liquid phase (for which convenient units are say $\mathrm{g} / \mathrm{L}$ ). The various experimental methods are covered in a recent review by Seidel-Morgenstern (2004). These can be classified into two broad categories: static and dynamic. In the former, an amount of adsorbent is contacted with a known volume $(V)$ of solution with an initial concentration $\left(c_{\text {start }}\right)$ of the solute. The concentration is then monitored until the equilibrium value $\left(c_{0}\right)$ is attained. A material balance then gives the amount adsorbed

$$
\Delta m_{\mathrm{ads}}=V\left(c_{\mathrm{start}}-c_{0}\right)
$$

assuming that, initially, the adsorbent is clean of the adsorbed component. The value of $\Delta m_{\mathrm{ads}}$ is then used to give the point on the isotherm, that is $q\left(c_{0}\right)$. There is a modification to this 
method which involves regenerating the adsorbent with a flow of eluent. This is continued until the concentration of the solute in the eluent reduces to zero. The total volume of eluent is collected, mixed and analysed to give an "average" solute concentration. This approach is a double-check on the amount adsorbed: assuming that regeneration is complete, the material balance should then give the same value of $\Delta m_{\text {ads }}$ determined from Equation (1). The whole procedure is then repeated with a different starting concentration $\left(c_{\text {start }}\right)$ which gives a different final (or equilibrium) concentration $\left(c_{0}\right)$. There are two drawbacks with the static approach: the time and material requirements can be prohibitive, and the equilibrium concentration $\left(c_{0}\right)$ is the value at the end of the experiment rather that at the start.

For the dynamic category, the adsorbent is contained as a packed column with a solution containing the solute as a feed. Then, at time zero, some change is made to the feed concentration of the solute. Information on the adsorption isotherm is then obtained from the variation with time of the solute concentration in the outlet flow - that is, $c(t)$. This "change" is conveniently obtained by increasing the feed concentration from zero to a value of $c_{0}-$ the variation of $c(t)$ would then be the breakthrough curve. Alternatively, the change might be to reduce the feed concentration from $c_{0}$ to zero - this variation of $c(t)$ is sometimes known as the washout curve. The use of a step-change in concentration is termed frontal analysis (FA), for which the equilibrium value of $q$ is obtained from

$q=\frac{Q \int_{0}^{\infty}\left[c_{0}-c(t)\right] \mathrm{d} t-V c_{0}}{W}$

where $V$ is the total empty space in the system between the valve and detector, $Q$ is the volumetric flow rate and $W$ is the mass of adsorbent. The selection of the correct value of $V$ is especially important when the solute is not strongly adsorbed and the integral is not large (Gritti and Guiochon, 2005a). Furthermore, the value of $Q$ should be maintained as constant 
as possible (Gritti and Guiochon, 2005b): an increase in flow rate gives a slight increase in the amount adsorbed because of the increase in column pressure. An advantage of FA is that it is based on a material balance and is independent of any mass-transfer limitations or axial dispersion.

The perturbation method is a variation on the FA method. This involves setting the feed concentration to a particular value $\left(c_{0}\right)$, and then adding "small" pulses of increasing size. From this set of results, the isotherm gradient is determined at the value of $c_{0}$. The whole procedure is then repeated at various values of $c_{0}$, starting at zero. The complete isotherm is finally obtained by integration of the set of gradients.

Consider now an "efficient" adsorption column: this is defined as a column in which the mass transfer is rapid and axial dispersion can be ignored. Consider now a pulse injection of the adsorbed component: this is obtained by increasing the inlet concentration of the solute from zero to a finite value and then back to zero. In this case, the passage of the pulse through the column will consist of a "sharp" front and a "dispersive" front. The degree of dispersion is determined by the curvature of the isotherm; each point $(c)$ on the isotherm will travel at a speed determined by the isotherm gradient. This is termed elution by characteristic point (ECP), the advantage of which is that a significant part of the isotherm can be determined from a single experiment.

The method proposed in this paper is distinctive in that our intention is to measure the adsorption isotherm by monitoring the variation in the volumetric flow rate leaving the column rather than by monitoring the solute concentration. There are a number of reasons why we are proposing such a method. First, to date all previous work in the groups at Strathclyde, Loughborough and Teesside has been in the gas phase. This is therefore a logical extension to the liquid phase. Second, our expertise is a method to measure small changes in flow rate and the application to material balances in various types of system. The method can 
be summarised by considering that a flow resistance is placed downstream of the adsorption column. Assuming that the flow regime is laminar, the pressure drop $(\Delta P)$ is related to the volumetric flow rate leaving the adsorption column $(Q)$ by the Hagen-Poiseuille equation

$\Delta P=k \mu Q$

where $\mu$ is the viscosity and $k$ is a tubing constant. It is helpful at this stage to consider an order of magnitude comparison between gas and liquid systems. Consider the adsorption of a component (solute) present at say $1 \%$ in a non-adsorbed mobile phase: in each case, there will be a reduction in the column outlet flow rate as the component passes leaves the mobile phase and passes into the adsorbed phase. The volume of a gas is typically three orders of magnitude greater than a liquid, however the viscosity of a liquid is typically two orders of magnitude greater than a gas. This would suggest that the application of Equation (4) to the measurement of changes in liquid flow rate due to adsorption might only be an order of magnitude less sensitive than for gases - which might be challenging - but is certainly worthy of further investigation.

The implication of trying to monitor adsorption from the column outlet flow rate in a liquid system is that the volumetric flow rate of the feed should be kept as constant as possible, especially where the solute is present at low concentrations. Gritti and Guiochon (2004) carried out an HPLC investigation on the adsorption of phenol using a mixture of water and methanol as the mobile phase. They found that the fluctuation in the pumping system was about $0.1 \%$, for a feed flow rate of $1 \mathrm{~mL} / \mathrm{min}$. In our case, by not operating under pressure we have the option of delivering the feed flow using an alternative method. The obvious solution might be some sort of pump capable of operating at low flow rates: that is, the syringe pump or piston pump. However, there are a number of potential problems with such a pump. First we are limited by the amount of liquid placed initially in the syringe, which could pose a problem if we require the flexibility of operating at higher flow rates and longer experimental 
times. Second, it is essentially a mechanical device in which the plunger is pushed in at a constant rate by a gear arrangement. Third, even if the gear arrangement is perfect, it requires a perfect cylinder to deliver a constant flow: this is a uniform diameter across the length of the cylinder.

There are three objectives to this research.

1. The first objective is to carry out a material balance on the column and to illustrate how the amount adsorbed in an experiment can be obtained from the variation in the volumetric flow rate leaving the column and known physical properties. Krige and Pretorius (1965) presented an analysis for the flow rate changes that occur due to the adsorption of a solute and specifically stated that the analysis could also be applied to the liquid phase. However, we can find no record in the literature of any investigation of flow-rate changes in the liquid phase. So, this is very much a pioneering - and challenging - investigation.

2. The second objective is to model the adsorption system and predict the actual variation in column outlet flow rate as the composition front enters, travels through and leaves the column. The shape of the composition front monitored by a detector at the outlet of the column is well-established in the literature for all types of adsorption system - plug flow, dispersed plug-flow. However, there is no such literature for the variation in column flow rate. We only know that the column outlet flow rate will drop as the front enters the column, and return to the original baseline as the front leaves the column: this would give, perhaps, a bath-shaped profile.

3. The third objective is to assess a possible experimental arrangement capable of detecting the changes in flow rate due to adsorption. Here, we consider a gravity-driven system in which a constant head of liquid is maintained across an arrangement of flow resistances. Much of the literature involves the use of gravity to drive liquid flows through a flow resistance in order to measure the viscosity. However, the design is such that the liquid level 
and the flow rate are not constant but decrease with time, for example in the determination of the viscosity of water at different temperatures (Digilov and Reiner, 2007). Our experimental arrangement will be a variation on the gravity-fed system in which the volumetric flow rate should remain constant during the experiment. There are three reasons for this choice. First, it is a research area for which there is limited published work. Second, it is a low-cost and robust arrangement that can be readily and easily constructed from available equipment. Third, by monitoring the pressure signal we will know instantly whether the column is saturated and the outlet flow is indeed constant.

\section{Theory of new method}

\section{Overall material balance on column}

Consider the schematic experimental arrangement shown in Figure 1 which consists of an adsorption column, a length of empty tubing of zero resistance and a length of resistance tubing. For the sake of simplicity, we consider a binary system of components A and B. Component B is non-adsorbed - and is the equivalent of the "carrier" in gas chromatography - while component A is capable of adsorption. Initially, the flow through the system is pure component $\mathrm{B}$ at a fixed volumetric value of $Q(0)$. Then, a step change is made in the composition of the feed such that the mass fraction of component $\mathrm{A}$ takes a value $x_{\mathrm{A}}$. Figure 1 shows the progress of the composition front through the system. The basic material balance is given by

$$
\text { in }=\text { out }+ \text { accumulation }
$$

In a time interval $\mathrm{d} t$, the total mass entering the system is equal to the total mass leaving plus the accumulation terms in the adsorbed and liquid phases. This can be written as

$$
Q(0) \rho_{\text {feed }} \mathrm{d} t=Q(t) \rho(t) \mathrm{d} t+\left(\mathrm{d} m_{\mathrm{A}}\right)_{\text {ads }}+\left(\mathrm{d} m_{\mathrm{A}}\right)_{\text {liq }}+\left(\mathrm{d} m_{\mathrm{B}}\right)_{\text {liq }}
$$


where $\rho_{\text {feed }}$ is the density of the feed mixture and $\rho(t)$ is the density of the outlet at time $t$. This is initially $\rho_{\mathrm{B}}$ (pure-component B) until breakthrough of the concentration front. Note that the presence of the delay volume ensures that for the duration of the experiment, pure component $\mathrm{B}$ is located in the measurement resistance. This can also be written as

$$
[Q(0)-Q(t)] \rho_{\text {feed }} \mathrm{d} t+Q(t)\left[\rho_{\text {feed }}-\rho(t)\right] \mathrm{d} t=\left(\mathrm{d} m_{\mathrm{A}}\right)_{\text {ads }}+\left(\mathrm{d} m_{\mathrm{A}}\right)_{\text {liq }}+\left(\mathrm{d} m_{\mathrm{B}}\right)_{\text {liq }}
$$

The second term on the left-hand side is equal to the two accumulation terms in the liquid phase. This allows Equation (6) to be simplified to

$$
[Q(0)-Q(t)] \rho_{\text {feed }} \mathrm{d} t=\left(\mathrm{d} m_{\mathrm{A}}\right)_{\text {ads }}
$$

which can then be integrated to obtain the amount adsorbed over an experiment.

$$
\left(\Delta m_{\mathrm{A}}\right)_{\mathrm{ads}}=\rho_{\text {feed }} \int_{0}^{\infty}[Q(0)-Q(t)] \mathrm{d} t
$$

The value of the integral can be simply determined from the variation of the outlet flow rate with time. The use of infinity as a limit of integration requires further explanation: this simply means the time taken to reach the new steady state in the column. The advantage of this continuous monitoring is to ensure that the new steady state is definitely attained in the column. Consider that the first experiment is carried out with a mass fraction of component A of 0.01 . The whole procedure would then be repeated with mass fractions of $0.02,0.03$ and so on up to say 0.1 . Note that the value of $\rho_{\text {feed }}$ would be different for each mixture, although this type of information is readily available from the literature. An important consideration at this stage is the heat of reaction and the implications for Equation (8). Assuming the system temperature can return to the starting value before the composition front leaves the delay volume, this should ensure that the material balance is not affected by any temporary increase or reduction in temperature. 
We now return to the evaluation of the integral, which will have the dimensions of volume. This could be evaluated with a direct-reading meter, but for precise work this is best achieved by measuring the pressure drop across the flow resistance indicated in Figure 1. Writing Equation (4) for the initial situation

$P_{2}(0)-P_{3}=k_{\mathrm{F}} \mu_{\mathrm{B}} Q(0)$

and then for the situation at any time $t$, we have

$P_{2}(t)-P_{3}=k_{\mathrm{F}} \mu_{\mathrm{B}} Q(t)$

Equations (9) and (10) can be substituted into (8) to give

$\left(\Delta m_{\mathrm{A}}\right)_{\mathrm{ads}}=\frac{\rho_{\text {feed }}}{k_{\mathrm{F}} \mu_{\mathrm{B}}} \int_{0}^{\infty}\left[P_{2}(0)-P_{2}(t)\right] \mathrm{d} t$

Therefore, the amount adsorbed during the experiment is determined by monitoring the variation of the pressure $P_{2}(t)$ with time, the density of the mixture, the viscosity of component B and a constant dependent on the dimensions of the tube.

\section{Material balance on component $A$}

The material balance for a non-reaction system is given by

$$
\text { in }=\text { out }+ \text { accumulation }
$$

In a time interval $\mathrm{d} t$, the amount of component $\mathrm{A}$ entering the system is equal to the total mass leaving plus the accumulation terms in the adsorbed and liquid phases. This can be written as

$Q(0) c_{0} \mathrm{~d} t=Q(t) c(L, t) \mathrm{d} t+\left(\mathrm{d} m_{\mathrm{A}}\right)_{\text {ads }}+\left(\mathrm{d} m_{\mathrm{A}}\right)_{\text {liq }}$

where $c(L, t)$ is the liquid-phase concentration of component A leaving the column. If we consider a time before the start of breakthrough of component $\mathrm{A}$, then the first term on the right-hand side becomes zero, and we can rearrange to a more convenient form 
$\frac{\left(\mathrm{d} m_{\mathrm{A}}\right)_{\mathrm{ads}}}{\mathrm{d} t}+\frac{\left(\mathrm{d} m_{\mathrm{A}}\right)_{\text {liq }}}{\mathrm{d} t}=Q(0) c_{0}$

This means that the sum of the two differential terms must be zero. We can also rearrange Equation (7) to give the differential balance on the total amount adsorbed in the column

$\frac{\left(\mathrm{d} m_{\mathrm{A}}\right)_{\mathrm{ads}}}{\mathrm{d} t}=[Q(0)-Q(t)] \rho_{\text {feed }}$

We assume equilibrium between the amount of $\mathrm{A}$ in both phases, in which case the ratio of the two differential terms is equal to a constant: this means that before the start of breakthrough of component $\mathrm{A}$, value of $Q(t)$ must remain at a constant value. This is an important finding, since it helps to determine the variation of the column outlet flow rate.

\section{Relation of variation in flow rate to concentration front}

It is helpful to start by considering Figure 2 which shows the passage of a concentration front through an adsorption column. This is a special case in which the shape and width of the front remains constant. In practical terms, such a concentration front might be obtained by adding a small flow of the adsorbed component A into a non-adsorbed liquid, and allowing the flow of component A to increase linearly with time until the required composition. We know from the previous sub-section that while the concentration front is contained entirely within the column, the column outlet flow rate will remain at a constant value. For the sake of convenience, this will be termed the plateau value $\left(Q_{\text {plat }}\right)$. However, as soon as the front reaches the end of the column - this is shown as the fifth series (dotted line) in Figure 2 - the column outlet flow rate will start to increase. This is the start of the breakthrough which is complete by the sixth series. By this time, the outlet flow rate will have returned to the original value of $Q(0)$.

We are also interested to determine the actual variation in the column outlet flow rate - that is $Q(t)$ - at breakthrough of the concentration front. This will be important in the next section, 
as we will be interested to determine the variation in $Q(t)$ for a number of concentration-front shapes. From intuition and observation, we know that the variation of $c(t)$ and $Q(t)$ tend to occur in tandem. During breakthrough, the value of $Q(t)$ is greater than $Q_{\text {plat }}$ because of component A leaving the adsorbed phase and entering the liquid phase. This means that we can state that

$Q(t)-Q_{\text {plat }} \propto Q(t) c(t)$

This can be written at any time $t$, and at the completion of breakthrough. The two equations are then combined to give

$\frac{c(t)}{c_{0}}=\frac{Q(t)-Q_{\text {plat }}}{Q(0)-Q_{\text {plat }}}\left[\frac{Q(0)}{Q(t)}\right]$

This is important since it indicates that the shape of the concentration front is almost the same as the shape of the variation of $Q(t)$ during breakthrough.

\section{The ideal variation in flow rate}

Before the modelling section, it is first helpful to examine the "ideal" variation of flow rate leaving the column. In order to streamline explanations, it is helpful to employ a parameter $(r)$, which is the ratio of the flow rate leaving the column at time $t$, to the initial value:

$r=\frac{Q(t)}{Q(0)}$

We now consider the properties of the feed. Consider first a batch system of components A and B. Assuming these components form an ideal mixture, the volume of the mixture $(V)$ can be written in terms of the specific volumes and masses of the two components by

$V=m_{\mathrm{A}} v_{\mathrm{A}}^{0}+m_{\mathrm{B}} v_{\mathrm{B}}^{0}$ 
where the superscript 0 refers to the property of the pure liquid at the temperature and pressure of the system.

Consider now a situation in which component $\mathrm{A}$ is removed from the mixture, as would be in the case of contact with an adsorbent of high affinity. There will obviously be a reduction in the total volume, and the fractional change is given by:

$$
\frac{\Delta V}{V}=\frac{-x_{\mathrm{A}} v_{\mathrm{A}}^{0}}{x_{\mathrm{A}} v_{\mathrm{A}}^{0}+x_{\mathrm{B}} v_{\mathrm{B}}^{0}}
$$

which is obtained by simply dividing top and bottom by the total mass.

This means that the ideal variation in flow rate from the adsorption column would be:

$$
r=1(t<0) \quad r=1-\frac{x_{\mathrm{A}} v_{\mathrm{A}}^{0}}{x_{\mathrm{A}} v_{\mathrm{A}}^{0}+x_{\mathrm{B}} v_{\mathrm{B}}^{0}}\left(0<t<t_{\text {retn }}\right) \quad r=1\left(t>t_{\text {retn }}\right)
$$

where $t_{\text {retn }}$ is the retention time for the (sharp) composition front. Assuming that the specific volumes of the two liquids are comparable, for $x_{\mathrm{A}}=0.01$ there will be approximately a $1 \%$ reduction in the volumetric flow rate leaving the column as the composition front passes through the column. In order to obtain this "ideal" profile, we have assumed the concentration profile is a sharp front (instantaneous equilibrium and no axial dispersion) and that component $\mathrm{A}$ is strongly adsorbed (all of component A passes into the adsorbed phase). This ideal profile has limitations, but it does provide a useful comparison for the modelling.

\section{Modelling of variation of column outlet flow rate with time}

\section{Influence of shape of concentration front}

From the previous section, the column outlet flow rate $(Q(t))$ will start at the baseline value $(Q(0))$, then reduce to the plateau value $\left(Q_{\text {plat }}\right)$ as the concentration front passes through the column, and finally return to the baseline value. The variation in the outlet concentration 
$(c(t))$, however, will have a different shape: "nothing" will be apparent until the concentration front leaves the column, in which case there will be a "sweep" or sharp transition to the concentration of component $\mathrm{A}$ in the feed. In this section, the objective is to model the actual variation in $Q(t)$ for a variety of concentration front shapes or variation.

For a single adsorbable component, the material balance (Seidel-Morgenstern, 2004) is written as

$$
\frac{\partial c}{\partial t}+\frac{1-\varepsilon}{\varepsilon} \frac{\partial q(c)}{\partial t}+u \frac{\partial c}{\partial z}=D_{L} \frac{\partial^{2} c}{\partial z^{2}}
$$

where $u$ is the linear velocity, $\varepsilon$ is the voidage in the column and $z$ is the axial position along the column. The parameter $q$ is the adsorbed-phase concentration of component A. The implication of the term $(c)$ next to $q$ allows the equilibrium adsorbed-phase concentration to be used: that is, the isotherm. The advantage of this approach is that the contributions to band broadening (axial dispersion and slow mass transfer processes) are all contained within a single apparent dispersion parameter $\left(D_{L}\right)$. For the sake of convenience, the adsorption equilibrium is represented by the Langmuir isotherm

$$
q=\frac{a c}{1+b c}
$$

where $a$ can be considered a type of Henry coefficient and $b$ is the Langmuir parameter. As $c$ tends to zero, the isotherm becomes linear. The isotherm gradient is given by

$$
\frac{\mathrm{d} q}{\mathrm{~d} c}=\frac{a}{(1+b c)^{2}}
$$

As the value of $c$ tends to zero, the isotherm tends to a linear form with $a$ equivalent to the Henry constant. Here, we consider the section of isotherm to be linear with gradient equal to a. Equation (21) can be solved with the relevant boundary conditions: for an adsorption experiment, initially the column is completely free of the adsorbed component (A), and then 
at $t=0$, the concentration of component $\mathrm{A}$ undergoes a step change to $c_{0}$. The solution is then given by $[c(z, t) ; q(z, t)]$ which shows how the concentration of component A varies with time at any location (axial position $z$ ) in the column. For a composition detector, located at the end of the column, the response is given by $c(L, t)$, where $L$ is the length of the column.

\section{Simplified solution of material balance}

We now return to the variation of the outlet flow rate from the column. In the previous section, an expression was given for $r$ assuming that component $\mathrm{A}$ is very strongly adsorbed: equivalent to assuming that the value of the parameter $a$ in Equation (22) is very large. In reality, we take account of the isotherm gradient and column voidage, and so the parameter $r$ will depend on the fraction of the adsorbed component that enters the adsorbed phase:

$$
r=1(t<0) \quad r=1-\left[\frac{(1-\varepsilon) a}{\varepsilon+(1-\varepsilon) a}\right] \frac{x_{\mathrm{A}} v_{\mathrm{A}}^{0}}{x_{\mathrm{A}} v_{\mathrm{A}}^{0}+x_{\mathrm{B}} v_{\mathrm{B}}^{0}}\left(0<t<t_{\text {retn }}\right) \quad r=1\left(t>t_{\text {retn }}\right)
$$

It is convenient to plot the profiles in terms of a dimensionless time $\left(t^{*}\right)$, which is defined by the time divided by the simple residence time $\left(t_{\mathrm{void}}\right)$. Figure 3 shows the idealised variations in the column outlet flow rate for a mole/mass fraction $\left(x_{\mathrm{A}}\right)$ of 0.06 and a voidage $(\varepsilon)$ of 0.75 . The two series correspond to different isotherm gradients: $a=3$ and $a=6$.

\section{Equilibrium-dispersion model}

From Equation (8), the amount adsorbed (value of $q$ ) depends only on the area enclosed by the variation in flow rate, and is independent of any band-broadening effects. This means that if axial dispersion (a finite value of $D_{L}$ ) is imposed on one of the profiles in Figure 3, the resulting profile will simply have a broader front as the concentration front leaves the column - but, the area formed by the variation $Q(t)$ bound by a horizontal line at $Q(0)$ will remain constant and independent of the value of $D_{L}$. 
Equation (21) can be solved to give an analytical solution (Levenspiel and Bischoff, 1963). This is shown modified so that the dimensionless time is based on the simple residence time in the column. Furthermore, this is the asymptotic form and assumes instantaneous equilibrium and a long column.

$$
\frac{c}{c_{0}}=\frac{1}{2} \operatorname{erfc}\left[\frac{1-\frac{t}{t_{\text {void }}} \frac{\varepsilon}{\varepsilon+(1-\varepsilon) a}}{2\left(N_{\mathrm{D}} \frac{t}{t_{\text {void }}} \frac{\varepsilon}{\varepsilon+(1-\varepsilon) a}\right)^{0.5}}\right]
$$

where $N_{\mathrm{D}}$ is the dispersion number which is equal to $\left(D_{L} / u z\right)$.

Figure 4 shows the variation in the column outlet flow rate for two values of the dispersion number: 0.01 for the solid line and 0.05 for the dotted line. This should be compared with the solid line of Figure 3, which corresponds to a zero dispersion number. In each of the cases shown in Figures 3 and 4, the concentration front entering the column is sharp; then, the effects of axial dispersion will cause the width of the concentration front to increase as it travels through the column.

\section{Experimental arrangement}

From the previous section, adsorption from the liquid phase will cause a reduction in the outlet flow rate from the column, and that this reduction is related to a number of factors. This means that there are two important implications for the design of an experimental arrangement to measure adsorption from the liquid phase.

1. A requirement of the material balance is that the flow rate of the feed $(Q(0))$ should be maintained as constant as possible. This will ultimately determine the range of applications of the method. For example, it will be impossible to monitor adsorption from the liquid phase where component $\mathrm{A}$ is present at a concentration of $100 \mathrm{ppm}$ if the flow rate of the feed can only be maintained to $\pm 5 \%$. 
2. We also require a sensitive method of measuring these small changes in flow rate. We have alluded to this previously by considering that the variation in the volumetric flow rate leaving the column can be inferred from the pressure drop across a length of resistance tubing.

The experimental arrangement is intended only to simulate the change in the outlet flow from the baseline value of $Q(0)$ to the plateau value of $Q_{\text {plat }}$. This will then be compared to the baseline variation in the value of $Q(0)$ (which we hope will remain as constant as possible), from which an assessment of the sensitivity of the arrangement can be inferred.

For this purpose we have used the gravity-driven system shown in Figure 5. There are two ways of ensuring that the flow rate remains constant in a gravity-driven system. First, we could employ a very large tank with a large cross-section and a large resistance to give a low flow rate so that the liquid level remains essentially constant during the experiment. However, there may be problems with evaporation from the liquid surface, especially for a volatile mobile phase. The alternative is to employ a weir system, where a flow rate of liquid higher than the system flow is directed into a beaker, and the excess flows over the side of the container or through a weir. We adopted the latter approach for this investigation.

The area surrounded by the dashed line is intended to represent the variation in column outlet flow rate that occurs in a liquid adsorption system when the concentration front is travelling though the column. Initially, valve V1 is open and valve V2 is closed and this represents the baseline state of the system. Then valve V2 is open to increase the flow rate through the measuring resistance $\left(k_{\mathrm{C}}\right)$. This would then represent what might happen during a desorption experiment, where the adsorbed component leaves the adsorbed phase and passes into the liquid phase. For example, in Figure 3 this would correspond to the change in outlet flow rate from the plateau value $\left(Q_{\text {plat }}\right)$ to the baseline value $(Q(0))$.

Because we only had a fixed amount of ethanol, it was necessary to recycle the flows back to the tank. The weir was simply a large hole in the side of the beaker with a large-diameter 
length of tubing to direct the flow to the return beaker. The liquid level in the supply beaker was approximately $30 \mathrm{~cm}$ above the bench surface. The "baseline" ethanol flow rate was determined by the flow resistances $k_{\mathrm{A}}$ and $k_{\mathrm{C}}$. These are different lengths of stainless-steel tubing with an internal diameter of about $1 \mathrm{~mm}$. The length of resistance $k_{\mathrm{A}}$ was about $50 \mathrm{~cm}$ and the length of resistance $k_{\mathrm{C}}$ was about $3 \mathrm{~cm}$ meaning that the ratio of $k_{\mathrm{A}}$ to $k_{\mathrm{C}}$ was close to 20. Resistance $k_{\mathrm{B}}$ had a length of about $20 \mathrm{~cm}$ but a much smaller bore (about $0.5 \mathrm{~mm}$ ), meaning that the value of $k_{\mathrm{B}}$ was perhaps an order of magnitude greater than $k_{\mathrm{A}}$. The two shut-off valves (V1 and V2) were Whitey ball-valves. The volumetric flow rate of ethanol was measured by directing the flow from resistance $\mathrm{C}$ into a measuring cylinder.

It could be argued that since this is a closed system, there should be no need to have the weir, since the liquid level in the tank should be constant. However, in a preliminary experimental arrangement without the weir, close inspection of the liquid level in the tank indicated that the liquid level might fluctuate in a typical hour time-scale by about $1 \mathrm{~mm}$. This corresponds to a change in pressure head of 0.1 mbar. The reasons for this may be evaporation of ethanol and any slight changes in the rate at which liquid is pumped back into the supply beaker and the time for which the ethanol flow rate is measured by directing the flow away from the return beaker. The pressure drop across resistance $k_{\mathrm{c}}$ was measured with a Validyne 55 pressure transmitter with $\mathrm{a} \pm 14$ mbar range corresponding to an output of $\pm 5000 \mathrm{mV}$. The signal voltage was measured every 1 second and recorded using a Pico data acquisition system.

\section{Experimental procedure and recorded pressure transmitter data}

1. The first stage was to prime the equipment. This was achieved by opening the two shutoff valves (V1 and V2) and switching on the pump, allowing the ethanol to flow through the whole system. Then valve V2 was closed and for the first experiment, the baseline value of $P_{2}(t)$ was monitored for 400 seconds. This was essential, as the likely applications (or limitations) of this equipment are likely to be determined by how constant we can maintain 
the baseline voltage and the main flow rate. This is shown in Figure 6. It can be seen that the signal drifts up by $0.3 \mathrm{mV}(0.00084 \mathrm{mbar})$ in the first 200 seconds, and then down by $0.2 \mathrm{mV}$ (0.00056 mbar) in the remaining 200 seconds. The baseline flow rate has a value $Q_{1}$.

2. For the second experiment, valve V2 was opened to allow ethanol to flow through resistance $k_{\mathrm{B}}$ and so increase the ethanol flow rate through the measuring resistance to a value $Q_{2}$. The valve was opened at a time of around 440 seconds. It can be seen that there is a steady increase in $P_{2}$, from $184.57 \mathrm{mV}$ to $202.06 \mathrm{mV}$ : a change of $17.49 \mathrm{mV}$ (0.049 mbar). The new steady-state took about 100 seconds to be achieved. Then, valve V2 was closed to stop ethanol flowing through resistance $k_{\mathrm{B}}$ and into the supply beaker. The valve was closed at a time of around 620 seconds. As expected, this leads to a reduction in the value of $P_{2}$ from 202.02 $\mathrm{mV}$ to $184.46 \mathrm{mV}$ : a change of $17.56 \mathrm{mV}$ (0.049 mbar). The complete pressure record for $P_{2}$ is shown in Figure 7, and it can be seen that there is a net drift by only $0.11 \mathrm{mV}(0.0003$ mbar), which is encouraging considering the experimental time.

\section{Calculation of equipment sensitivity for potential adsorption experiments}

For a favourable experimental design we require that the drifting should be as low as possible in Figure 6 and that the step-change in Figure 7 should be as large as possible. Consider the step-change experiment in which the initial flow rate is $Q_{1}$ and the final flow rate is $Q_{2}$. It is appropriate to be able to quantify how well the experimental arrangement might perform for adsorption experiments and for convenience the parameter of performance $(\alpha)$ is defined by

$$
\alpha=\frac{\left[\Delta P_{2}\right](\text { drift })(\mathrm{mV})}{\left[\Delta P_{2}\right](\text { step })(\mathrm{mV})} \times\left[\frac{Q_{2}}{Q_{1}}-1\right]
$$

Note that for a successful experimental arrangement, the value of $\alpha$ should be as small as possible. Let us consider a notional example. Consider that the drift over a particular time spell is $0.01 \mathrm{mV}$, and that the step change is $100 \mathrm{mV}$ for a fractional increase in flow rate of 
1\%. This would give a value of $10^{-6}$ which would be very favourable, since it would be capable of measuring tiny flow rate changes corresponding to systems where the adsorbate is present at low concentrations. As we shall see, the actual value of $\alpha$ for the current experimental arrangement is not as favourable. We now proceed to obtain an expression for $\alpha$ in terms of the various experimental parameters.

The first stage is to identify and quantify the possible sources of drifting in the baseline shown in Figure 6. Assuming laminar flow through both resistances $k_{\mathrm{D}}$ and $k_{\mathrm{F}}$, we can write

$$
P_{2}-P_{3}=\frac{k_{\mathrm{F}} \mu_{\mathrm{F}}}{k_{\mathrm{D}} \mu_{\mathrm{D}}+k_{\mathrm{F}} \mu_{\mathrm{F}}} \rho g h
$$

From Equation (27), we can identify three possible reasons to explain why the variation shown in Figure 6 is not a horizontal line. First, there may be variation in the level of ethanol in the tank. The weir is designed to maintain this level constant, but this may not be perfect. Second, there may be changes in the overall liquid temperature which will change the density. Third, over the course of the experiment, the temperatures in the two resistances may change by different amounts. Consider that the ethanol in resistance $k_{\mathrm{F}}$ changes by $0.1^{\circ} \mathrm{C}$ but the ethanol in resistance $k_{\mathrm{D}}$ stays at the same value. This effect is included because the liquid viscosity is a strong function of temperature (Yaws, 1999). From differentiation, these three sources of drifting (level, density and viscosity) are quantified as

$$
\begin{aligned}
& \Delta P_{2}(h)=\frac{\mu_{\mathrm{F}} k_{\mathrm{F}}}{\mu_{\mathrm{D}} k_{\mathrm{D}}+\mu_{\mathrm{F}} k_{\mathrm{F}}} \rho g \Delta h \\
& \Delta P_{2}(\rho)=\frac{\mu_{\mathrm{F}} k_{\mathrm{F}}}{\mu_{\mathrm{D}} k_{\mathrm{D}}+\mu_{\mathrm{F}} k_{\mathrm{F}}} g h \Delta \rho \\
& \Delta P_{2}(T)=\frac{k_{\mathrm{D}} k_{\mathrm{F}}}{\left(k_{\mathrm{D}} \mu_{\mathrm{D}}+k_{\mathrm{F}} \mu_{\mathrm{F}}\right)^{2}}\left(\mu_{\mathrm{D}} \Delta \mu_{\mathrm{F}}-\mu_{\mathrm{F}} \Delta \mu_{\mathrm{D}}\right) \rho g h
\end{aligned}
$$


The value of the drift term in Equation (26) is then simply the sum of these three terms. The next stage is to simplify the term in Equation (26) involving the ratio of $Q_{2}$ to $Q_{1}$. The "before" state of the system (before valve V2 is open) can be written as

$$
\begin{aligned}
& P_{2}-P_{3}=k_{\mathrm{F}} \mu_{\mathrm{F}} Q_{1} \\
& P_{1}-P_{3}=\left(\mu_{\mathrm{D}} k_{\mathrm{D}}+\mu_{\mathrm{F}} k_{\mathrm{F}}\right) Q_{1}
\end{aligned}
$$

and the "after" state can be written as

$$
\begin{aligned}
& \left(P_{2}+\Delta P_{2}(\text { step })\right)-P_{3}=k_{\mathrm{F}} \mu_{\mathrm{F}} Q_{2} \\
& P_{1}-P_{3}=\mu_{\mathrm{D}} k_{\mathrm{D}}\left(Q_{2}-Q_{3}\right)+\mu_{\mathrm{F}} k_{\mathrm{F}} Q_{2}
\end{aligned}
$$

Equations (31) to (34) can be solved to eliminate $Q_{3}$ and give an expression for the ratio of the "initial" and "final" ethanol flow rates. This can be simplified by assuming that the values of $\mu_{\mathrm{A}}$ and $\mu_{\mathrm{B}}$ are the same:

$$
\frac{Q_{2}}{Q_{1}}=1+\frac{k_{\mathrm{D}}}{k_{\mathrm{F}}}\left[1+\frac{k_{\mathrm{E}}}{k_{\mathrm{F}}}+\frac{k_{\mathrm{E}}}{k_{\mathrm{D}}}\right]^{-1}
$$

Our measurements indicate that opening the valve V2 increases the volumetric flow rate by about $15 \%$. We know that the ratio of $k_{\mathrm{D}}$ to $k_{\mathrm{F}}$ is approximately 20 and so from Equation (35) the ratio of $k_{\mathrm{E}}$ to $k_{\mathrm{D}}$ is about 6 . This is in accordance with our expectations: the resistance of a length of tubing is inversely proportional to the internal diameter to the fourth power (Coulson and Richardson, 1999). The form of Equation (35) can be checked by intuition. As the value of $k_{\mathrm{E}}$ is increased, the ratio of the two flow rates tends to unity: opening the valve V2 will have zero effect on the flow rate through resistance $F$.

We return to the final term in Equation (26). Subtracting Equation (31) from (33) we obtain:

$$
\Delta P_{2}(\text { step })=k_{\mathrm{F}} \mu_{\mathrm{F}}\left(Q_{2}-Q_{1}\right)
$$


and then using Equation (35) we have the useful form

$\Delta P_{2}($ step $)=\rho g h \frac{k_{\mathrm{D}}}{k_{\mathrm{D}}+k_{\mathrm{F}}}\left[1+\frac{k_{\mathrm{E}}}{k_{\mathrm{F}}}+\frac{k_{\mathrm{E}}}{k_{\mathrm{D}}}\right]^{-1}$

Once again, Equation (37) can be checked to confirm what we expect from intuition: a zero value of $k_{\mathrm{F}}$ will give an expected zero step-change in $\Delta P_{2}$. Furthermore, an infinite value of $k_{\mathrm{E}}$ will make zero difference to the flow rate and an expected zero step-change of $\Delta P_{2}$. Finally, we can combine Equations (28) to (30), (35) and (37) to obtain:

$\alpha=\frac{\Delta h}{h}+\frac{\Delta \rho}{\rho}+\frac{k_{\mathrm{D}}}{k_{\mathrm{D}}+k_{\mathrm{F}}}\left[\frac{\Delta \mu_{\mathrm{F}}-\Delta \mu_{\mathrm{D}}}{\mu}\right]$

This is interesting for a number of reasons. Note that the resistance $k_{\mathrm{E}}$ does not appear in the above equation. This is what would be expected: the resistance $k_{\mathrm{E}}$ is only used to change the system flow. If we assume that variation in the level of liquid $(h)$ is the main reason for the baseline drift, then the value of $\alpha$ is independent of the values of the two flow resistances. This is because as the values of $k_{\mathrm{D}}$ and $k_{\mathrm{F}}$ are changed, both the drift and step-change values of $\Delta P_{2}$ in Equation (26) change by the same amount. If, however, we assume that the main source of baseline drift is the temperature changing by different amounts in the two resistances (so that the values of $\Delta \mu_{\mathrm{D}}$ and $\Delta \mu_{\mathrm{F}}$ are not the same), then this can be reduced by reducing the value of the main-flow resistance $\left(k_{\mathrm{D}}\right)$.

We can now calculate the actual value of $\alpha$ for the experiments shown in Figures 6 and 7. From Figure 6, the average drift in baseline over a 100 -second timescale is about $0.1 \mathrm{mV}$. From Figure 7, an increase of the flow through the measuring resistance of $15 \%$ corresponds to a step change in the signal of about $20 \mathrm{mV}$. These parameters show that

$$
\alpha=\frac{0.1}{20} \times(1.15-1)=0.00075
$$


This is the order of $10^{-4}$ of the original flow rate. If we assume a resolution of one part in 100 , this would mean that we could use the current experimental arrangement to measure the adsorption of solutes present at levels of the order of $10^{-2}$. A typical example might be an investigation of a new adsorbent to dry an ethanol stream containing $5 \%$ of water. The natural question is then how we might improve the arrangement to measure the adsorption of solutes present at much lower concentration levels - say an order of magnitude reduction to 1000 ppm, since this would open up a large number of new applications.

\section{Discussion}

1. We first of all consider whether it is possible to determine the source of the baseline drifting in Figure 6. This will be achieved by predicting $\alpha$ according to Equation (38). The obvious reason might be that the liquid level $(h)$ in the tank will vary with time. Observation would suggest that the liquid level might be maintained to perhaps $0.5 \mathrm{~mm}$ for which

$$
\alpha=\frac{\Delta h}{h}=\frac{0.5}{300}=0.0017
$$

This is about twice the actual value (0.00075), and so would suggest that $h$ might be maintained to around $0.25 \mathrm{~mm}$ : the liquid level may indeed be the major reason for the drift in the baseline. The second term in Equation (38) concerns drifting due to the change in density. The densities of ethanol at $21.0^{\circ} \mathrm{C}$ and $21.1^{\circ} \mathrm{C}$ are $791.4 \mathrm{~kg} / \mathrm{m}^{3}$ and $791.3 \mathrm{~kg} / \mathrm{m}^{3}$ respectively. Therefore, if the temperature of the entire liquid column varies by $0.1^{\circ} \mathrm{C}$, then we can write

$$
\alpha=\frac{\Delta \rho}{\rho}=\frac{0.1}{790}=0.00013
$$

This is a factor of six smaller than the actual value $(0.00075)$, and would suggest that this is not a likely reason for the baseline drift. We finally consider that the temperature in the two resistances might not be the same. The viscosity of a liquid is very sensitive to temperature: 
for ethanol, the viscosities at $20.0^{\circ} \mathrm{C}$ and $20.1^{\circ} \mathrm{C}$ are 1.145 and $1.143 \mathrm{cP}$ respectively. Consider that the temperature of ethanol in resistance $k_{\mathrm{F}}$ increases by $0.1{ }^{\circ} \mathrm{C}$ and that the temperature of resistance A remains the same. We can then write

$$
\alpha=\frac{k_{\mathrm{D}}}{k_{\mathrm{D}}+k_{\mathrm{F}}}\left[\frac{\Delta \mu_{\mathrm{F}}-\Delta \mu_{\mathrm{D}}}{\mu}\right]=\frac{20}{20+1}\left[\frac{0.002}{1.145}\right]=0.0017
$$

This is significant, and would indicate that insulation of the experimental arrangement from changes in ambient temperature is more important than we had considered at the outset. At present, the whole arrangement is simply placed on the top of a bench.

From the three calculations, there may be two ways in which the experimental arrangement could be improved to reduce the level of drifting. First, to increase the value of $h$ by say a factor of 10 and place the liquid beaker close to the roof of the laboratory. Second, to increase the value of $k_{\mathrm{F}}$ relative to the value of $k_{\mathrm{D}}$. The current values are 20 and 1 , respectively; an improvement would be to change these values to 14 and 7 so that the sum remains constant. These changes might reduce the drifting by a factor of 10 .

2. There is another quite different reason why the baseline might vary with time. The liquid is likely to contain particles that originate from the equipment, and the associated wetted surfaces. As these particles are carried around the system, they may cause temporary blockages in the capillary tubes. Furthermore, according to the classical theory of Einstein, the presence of particles as a suspension will cause a slight increase in the viscosity $(\mu)$. This may vary with time as the particles settle and pass into the flowing liquid.

3. There are a number of ways in which the experimental arrangement might be improved. The flow resistances are various length of stainless-steel tubing with an internal diameter of either $0.5 \mathrm{~mm}$ or $1 \mathrm{~mm}$. The same values of resistance might be achieved by using nylon tubing with larger inside diameters and longer lengths. The larger diameter might be less 
susceptible to any entrained particles in the ethanol. Another possible modification concerns the supply beaker: the same beaker is used for both liquid flows. It is possible that when the valve $\mathrm{V} 2$ is opened to allow the flow through resistance $k_{\mathrm{E}}$, this might cause a sudden (but tiny) drop in the liquid level causing a slight reduction in the flow through resistance $k_{\mathrm{D}}$. This could be avoided by an extra supply beaker for the flow through resistance $k_{\mathrm{E}}$.

4. There are two potential problems regarding the transfer of heat between the liquid flowing through the capillary tubes and the surroundings. First, as discussed in Point 1, there is the potential for local changes in ambient temperature to change the liquid viscosity in each resistance by different amounts. To this end, we would require the overall heat-transfer coefficient $(U)$ to be as low as possible. However, adsorption in the liquid phase can be a fairly exothermic process (where the temperature change can exceed $10^{\circ} \mathrm{C}$ ). To that end, we would require the "heated" liquid mixture leaving the adsorption column to "lose" this excess heat as quickly as possible: major requirements are that the viscosity of liquid in the measurement resistance $\left(k_{\mathrm{F}}\right)$ should remain constant and that the whole system return to ambient temperature before completion of the experiment. To this end, we would require that $U$ should be as high as possible.

The flow through the tubing is laminar for which heat is transferred from the inside of the tube to the liquid by conduction. This is a special case for which the Nusselt number $=3.66$ (constant wall temperature). This allows determination of the heat-transfer coefficient $\left(h_{\text {con }}\right)$ :

$$
\mathrm{Nu}=\frac{h_{\text {con }} d}{k} \rightarrow h_{\text {con }}=\frac{3.66 \times 0.2}{0.001}=732\left(\mathrm{~W} / \mathrm{m}^{2} \mathrm{~K}\right)
$$

for a tube with an inside diameter of $1 \mathrm{~mm}$ (ethanol has a $k$ value of $0.2 \mathrm{~W} / \mathrm{mK}$ ). Depending on the mode of heat transfer between the surroundings and the tube wall, the value of $U$ might vary from 10 to $500 \mathrm{~W} / \mathrm{m}^{2} \mathrm{~K}$. This might suggest that the best choice would be to place the capillaries and associated tubing in a constant-temperature enclosure with a high value of $U$. 
5. A good choice for a first experimental investigation would be the water-ethanol system. Lau et al. (2004) used a column of length $47 \mathrm{~cm}$ and diameter $5 \mathrm{~cm}$ packed with spherical beads of $3 \mathrm{~A}$ zeolite. The intention was to dry a mixture containing about $3 \%$ by weight of water. A flow rate of $16.5 \mathrm{~mL} / \mathrm{min}$ was set and the column outlet analysed to obtain the breakthrough curve $(c(L, t))$. This started at a time of about three hours and was complete by about seven hours. Adsorption of water onto zeolite is an exothermic process, and the concentration front was accompanied by a thermal wave with a peak temperature $20^{\circ} \mathrm{C}$ greater than the ambient temperature. According to the equilibrium loading data, the water is strongly adsorbed, with the value of $a$ greater than 5. A better choice of operating conditions might be to reduce the column volume by a factor of 100 , the diameter by a factor of 5 and the flow rate by a factor of 10 . This would allow the experimental time to be reduced by a factor of 10 , and suppress the formation of any thermal wave through the column. Furthermore, a major advantage of monitoring the flow rate is that a key parameter is the fractional reduction in column outlet flow rate that occurs straightaway when the concentration front enters the column. This fractional reduction is independent of the amount of packing, although it will depend on the voidage in the column.

6. We now return to the component material balance shown in Equation (12). This can be written in a more-convenient form and then integrated to give:

$$
\left(\Delta m_{\mathrm{A}}\right)_{\mathrm{ads}}+\left(\Delta m_{\mathrm{A}}\right)_{\mathrm{liq}}=Q(0) \int_{0}^{\infty}\left[c_{0}-c(t)\right] \mathrm{d} t+\int_{0}^{\infty} c(t)[Q(0)-Q(t)] \mathrm{d} t
$$

The first integral term is the "standard" term for breakthrough of the concentration front. The second integral term is a correction to allow for the variation in the outlet flow rate with time. The function within the integral will take the form of a peak since it will be zero at time zero, and then zero after breakthrough of the concentration front is complete. For a "vertical" or "sharp" concentration front, the integral will have a zero value. Indeed, the value of the 
integral will increase with the width of the concentration front. This has important implications. Since the area given by Equation (8) is fixed for a particular value of $(\Delta m)_{\mathrm{ads}}$, then the individual integrals in Equation (39) will vary with the width of the concentration front.

7. In Equations (18) and (19), it was assumed that the liquid mixture is ideal. In reality, Equation (19) should be re-written as

$$
\frac{\Delta V}{V}=\frac{x_{\mathrm{B}}\left(v_{\mathrm{A}}^{0}-v_{\mathrm{B}}\right)-x_{\mathrm{A}} v_{\mathrm{A}}}{x_{\mathrm{A}} v_{\mathrm{A}}+x_{\mathrm{B}} v_{\mathrm{B}}}
$$

where $v_{\mathrm{A}}$ and $v_{\mathrm{B}}$ are the partial specific volumes of components $\mathrm{A}$ and $\mathrm{B}$, which vary with composition of the liquid mixture. Typically, the difference between using Equation (19) and (40) might be of the order of a few \%.

\section{Conclusions}

For the measurement of adsorption of a single component from the liquid phase, the standard approach is to monitor the concentration of the adsorbed component in the outlet flow from the adsorption column. In this work, we consider how adsorption might be measured by monitoring the variation in the actual outlet flow rate. One advantage of this approach is that there will be a step-reduction in the outlet flow rate that occurs as soon as the concentration front enters the column; moreover, from the material balance this reduction will stay at a constant level before the start of breakthrough. This is preferable to the "concentration" approach, where it is necessary to wait until breakthrough of the front is complete, which can take a number of hours. A major requirement of the developed theory is that the flow rate of the feed to the adsorption column should be maintained as constant as possible: this then determines the sensitivity of the equipment. Our results would suggest that a gravity-driven system with a liquid head of $30 \mathrm{~cm}$ is capable of monitoring a strongly-adsorbed component 
present in the liquid phase at a mass fraction of about $1 \%$. The limiting factor is how constant the liquid level in the feed tank can be maintained. Increasing this height by a factor of 10 should allow the method to deal with a component present at a level of about $1000 \mathrm{ppm}$. An alternative for future investigations might be to replace the gravity-driven system with a series of syringe or piston pumps.

\section{Acknowledgement}

This work was supported by the Engineering and Physical Sciences Research Council (EPSRC) and the Nuffield Foundation (NAL/00624/G).

\section{Nomenclature}

a Gradient of isotherm

$c(L, t) \quad$ Concentration of component A in flow leaving column $(\mathrm{g} / \mathrm{L})$

$c_{0} \quad$ Concentration of component $\mathrm{A}$ in feed to column $(\mathrm{g} / \mathrm{L})$

$D_{L} \quad$ Effective axial dispersion coefficient in column $\left(\mathrm{m}^{2} / \mathrm{s}\right)$

$h \quad$ Liquid head $(\mathrm{cm})$

$h_{\text {con }} \quad$ Heat-transfer coefficient between inside tube wall and ethanol flow $\left(\mathrm{W} / \mathrm{m}^{2} \mathrm{~K}\right)$

$k_{\mathrm{D}} \quad$ Flow resistance to set initial flow $\left(\mathrm{m}^{-3}\right)$

$k_{\mathrm{E}} \quad$ Flow resistance to add extra ethanol flow $\left(\mathrm{m}^{-3}\right)$

$k_{\mathrm{F}} \quad$ Flow resistance to measure total ethanol flow leaving system $\left(\mathrm{m}^{-3}\right)$

$L \quad$ Length of column (cm)

$\left(m_{\mathrm{A}}\right)_{\text {ads }} \quad$ Mass of component $\mathrm{A}$ in adsorbed phase in the column (g)

$\left(m_{\mathrm{A}}\right)_{\text {liq }} \quad$ Mass of component A in liquid phase in the column $(\mathrm{g})$

$\left(m_{\mathrm{B}}\right)_{\text {liq }} \quad$ Mass of component B in liquid phase in the column $(\mathrm{g})$

$N_{\mathrm{D}} \quad$ Dispersion number

$P_{1} \quad$ Atmospheric pressure (Pa or bar) 


(1)

$P_{2} \quad$ Pressure used to monitor flow rate leaving system (Pa or bar)

$P_{3} \quad$ System discharge pressure (Pa or bar)

$q \quad$ Concentration of adsorbed component in adsorbed phase $(\mathrm{g} / \mathrm{L})$

$Q(t) \quad$ Volumetric flow rate leaving column at time $t(\mathrm{~mL} / \mathrm{min})$

$Q_{\text {plat }} \quad$ Constant-value value of $Q(\mathrm{t})$ before start of breakthrough $(\mathrm{mL} / \mathrm{min})$

$Q_{1} \quad$ Volumetric flow of ethanol in initial state (with $\mathrm{V} 1$ only open) $(\mathrm{mL} / \mathrm{min})$

$Q_{2} \quad$ Volumetric flow of ethanol after opening valve $\mathrm{V} 2(\mathrm{~mL} / \mathrm{min})$

$Q_{3} \quad$ Volumetric flow of ethanol through resistance B when valve $\mathrm{V} 2$ is open $(\mathrm{mL} / \mathrm{min})$

$r \quad$ Ratio of actual flow rate to initial flow rate leaving column

$t_{\text {retn }} \quad$ Time taken for (sharp) concentration front to emerge from column (s)

$t_{\text {void }} \quad$ Simple residence time in column (s)

$u$

Fluid-phase velocity in adsorption column $(\mathrm{m} / \mathrm{s})$

$U \quad$ Overall heat-transfer coefficient $(U)$ between ambient and ethanol $\left(\mathrm{W} / \mathrm{m}^{2} \mathrm{~K}\right)$

$v_{\mathrm{A}}^{0} \quad$ Specific volume of component A at the system pressure and temperature $(\mathrm{mL} / \mathrm{g})$

$v_{\mathrm{B}}^{0} \quad$ Specific volume of component B at the system pressure and temperature $(\mathrm{mL} / \mathrm{g})$

$V \quad$ Volume of liquid $(\mathrm{mL})$

W $\quad$ Mass of adsorbent $(\mathrm{g})$

$x_{\mathrm{A}} \quad$ Mass fraction of adsorbed component (A)

$x_{\mathrm{B}} \quad$ Mass fraction of non-adsorbed component (B)

$z \quad$ Axial location in column $(\mathrm{cm})$

$\alpha$

Performance of experimental arrangement

$\mu_{\mathrm{B}} \quad$ Viscosity of non-adsorbed component B $(\mathrm{kg} / \mathrm{ms})$

$\mu_{\mathrm{D}} \quad$ Viscosity of ethanol in resistance $\mathrm{D}(\mathrm{kg} / \mathrm{ms})$

$\mu_{\mathrm{E}} \quad$ Viscosity of ethanol in (flow-changing) resistance $\mathrm{E}(\mathrm{kg} / \mathrm{ms})$

$\mu_{\mathrm{F}} \quad$ Viscosity of ethanol in (flow-measurement) resistance $\mathrm{F}(\mathrm{kg} / \mathrm{ms})$ 
$\varepsilon \quad$ Column voidage

$\rho(t) \quad$ Density of outlet flow from column at time $t\left(\mathrm{~kg} / \mathrm{m}^{3}\right)$

$\rho_{\mathrm{B}} \quad$ Density of non-adsorbed liquid B $\left(\mathrm{kg} / \mathrm{m}^{3}\right)$

$\rho_{\text {feed }} \quad$ Density of feed to adsorption column $\left(\mathrm{kg} / \mathrm{m}^{3}\right)$

\section{References}

Chang, C-F., C-Y Chang, K-H Chen, W-T Tsai, J-L Shie and Y-H Chen, “Adsorption of naphthalene on zeolite from aqueous solution", Journal of Colloid and Interface Science, 277, 29-34 (2004)

Coulson, J.M. and J.F. Richardson, "Chemical Engineering: Volume 1", Butterworth Heinemann, Oxford (1999)

Digilov, R.M. and M. Reiner, "Mass-controlled capillary viscometer for a Newtonian liquid: Viscosity of water at different temperatures”, Review of Scientific Instruments, 78, 035112 (2007)

Gritti, F. and G. Guiochon, "Accuracy and precision of adsorption isotherm parameters measured by dynamic HPLC methods", Journal of Chromatography A, 1043, 159-170 (2004)

Gritti, F. and G. Guiochon, "Systematic errors in the measurement of adsorption isotherms by frontal analysis: Impact of the choice of column hold-up volume, range and density of data points”, Journal of Chromatography A, 1097, 98-115 (2005a)

Gritti, F. and G. Guiochon, "Effect of the flow rate on the measurement of adsorption data by dynamic frontal analysis”, Journal of Chromatography A, 1069, 31-42 (2005b)

Kays, W.M. and M.E. Crawford, “Convective Heat and Mass Transfer”, McGraw-Hill, New York (1993) 
Krige, G.J. and V. Pretorius, "Frontal Analysis Chromatography: Calculation of Flow Rate Changes due to Solute Sorption, and Retention Characteristics of Sharp Fronts", Analytical Chemistry, 37, 1186-1190 (1965)

Lau, A., B.D. Crittenden and R.W. Field, "Enahancement of liquid phase adsorption column performance by means of oscillatory flow: an experimental study", Separation and

Purification Technology, 35, 113-124 (2004)

Levenspiel, O. and K.B. Bischoff, Advances in Chemical Engineering, Vol 4, 95, Academic Press, New York (1963)

Roostaei, N., and F. Handan Tezel, "Removal of Phenol from Aqueous Solutions by Adsorption", Journal of Environmental Management, 70, 157-164 (2004)

Seidel-Morgenstern, A., "Experimental determination of single solute and competitive adsorption isotherms”, Journal of Chromatography A, 1037, 255-272 (2004)

Yaws, C.L., “Chemical Properties Handbook”, McGraw-Hill, New York (1993)

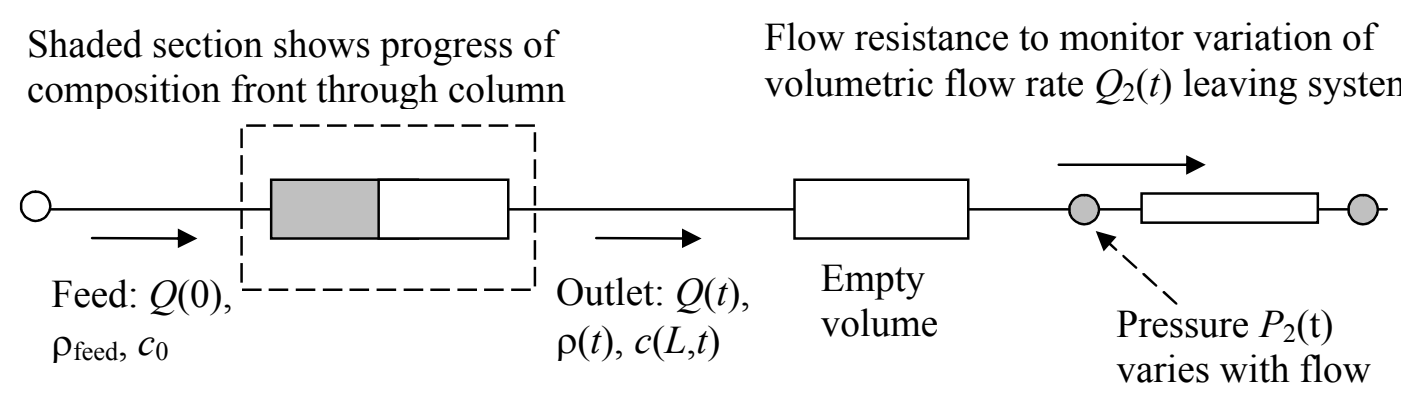

Figure 1: Schematic experimental arrangement for measuring adsorption in liquid systems. The empty volume is a key part of the experimental arrangement. It maintains a constant composition (component B) in the flow resistance while the composition front is travelling through the column. 


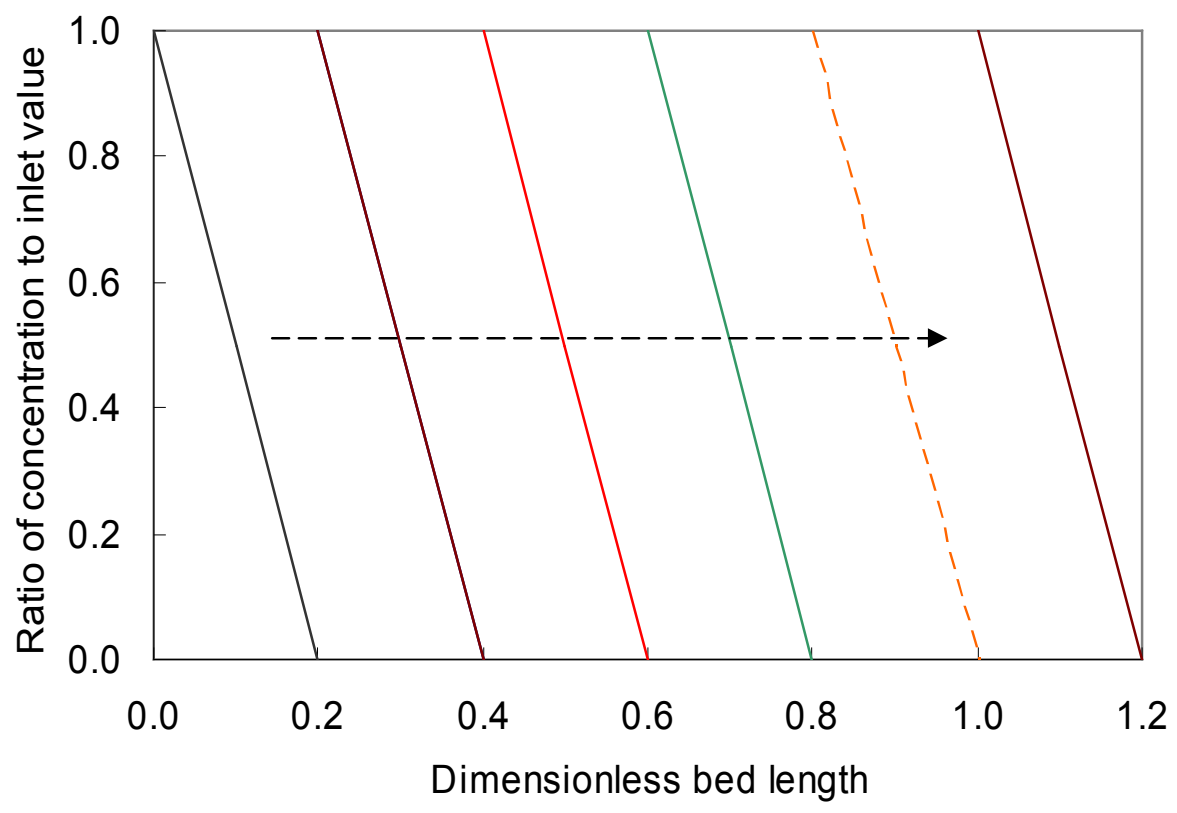

Figure 2: Passage of a concentration front of finite width through an adsorption column. The shape of the front remains constant because the dispersion effects are ignored. The arrow shows the progress of the front with time: the front shown with a dashed line corresponds to the start of breakthrough, and the final front corresponds to the completion of breakthrough.

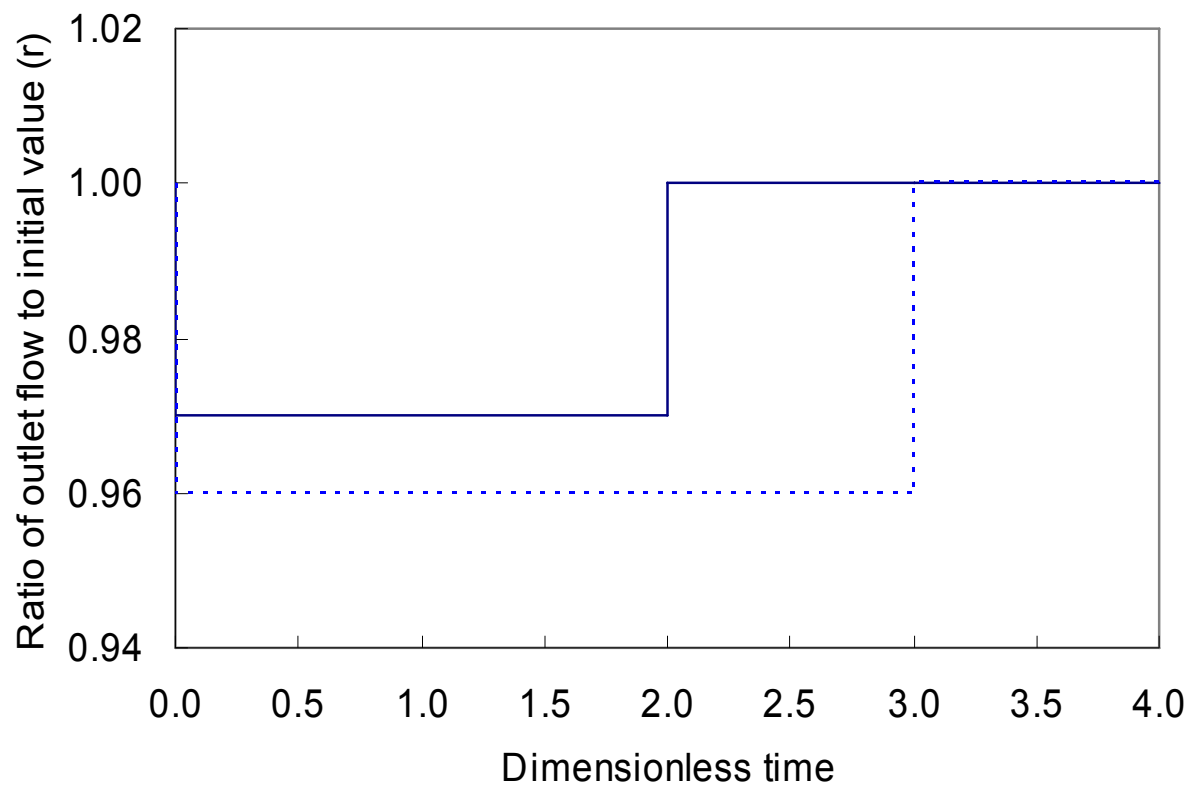

Figure 3: Idealised (linear isotherm, zero axial dispersion, instantaneous equilibrium) variation in the volumetric flow rate leaving the column. The dotted line corresponds to the more strongly-adsorbed component: $a=6$ compared to $a=3$. For each case, a sharp or vertical concentration front enters the column at time $=0$. 


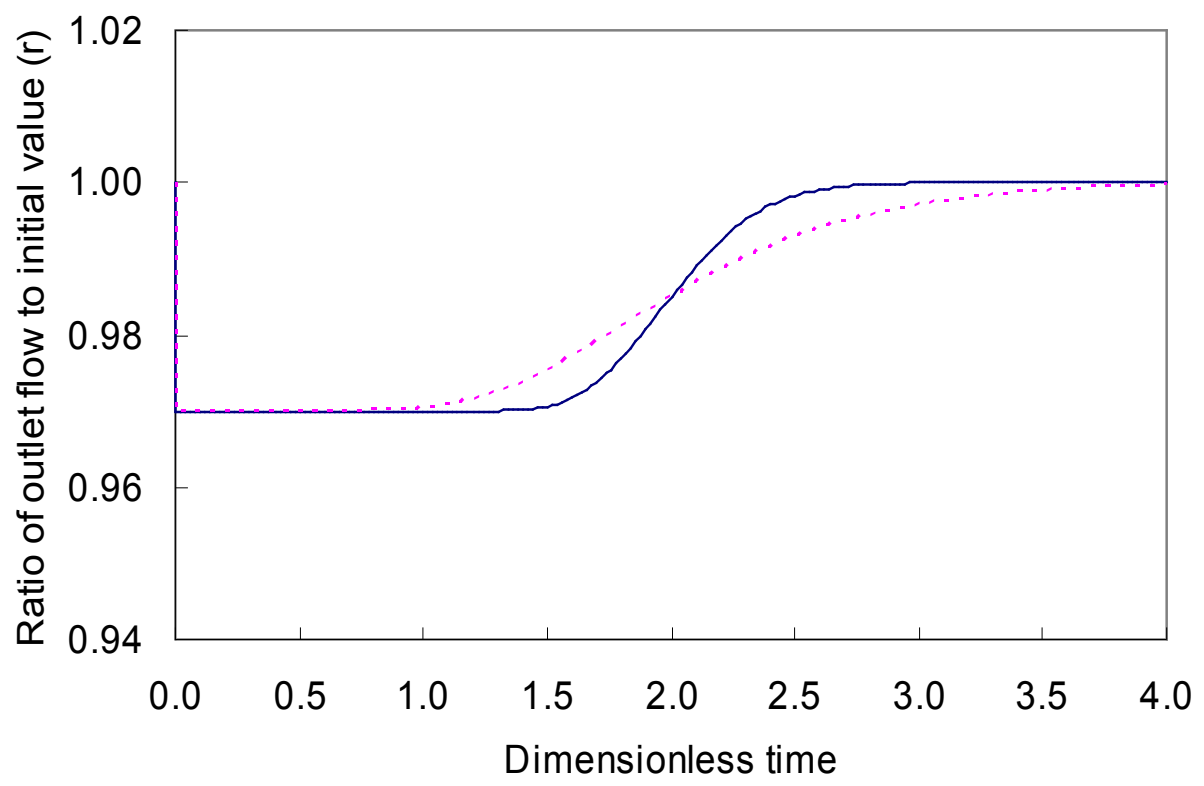

Figure 4: Actual variation in the column outlet flow rate for solution of the material balance with the inclusion of axial dispersion in the column. The solid line is for a dispersion number of 0.01 and the dotted line is for a dispersion number of 0.05 .

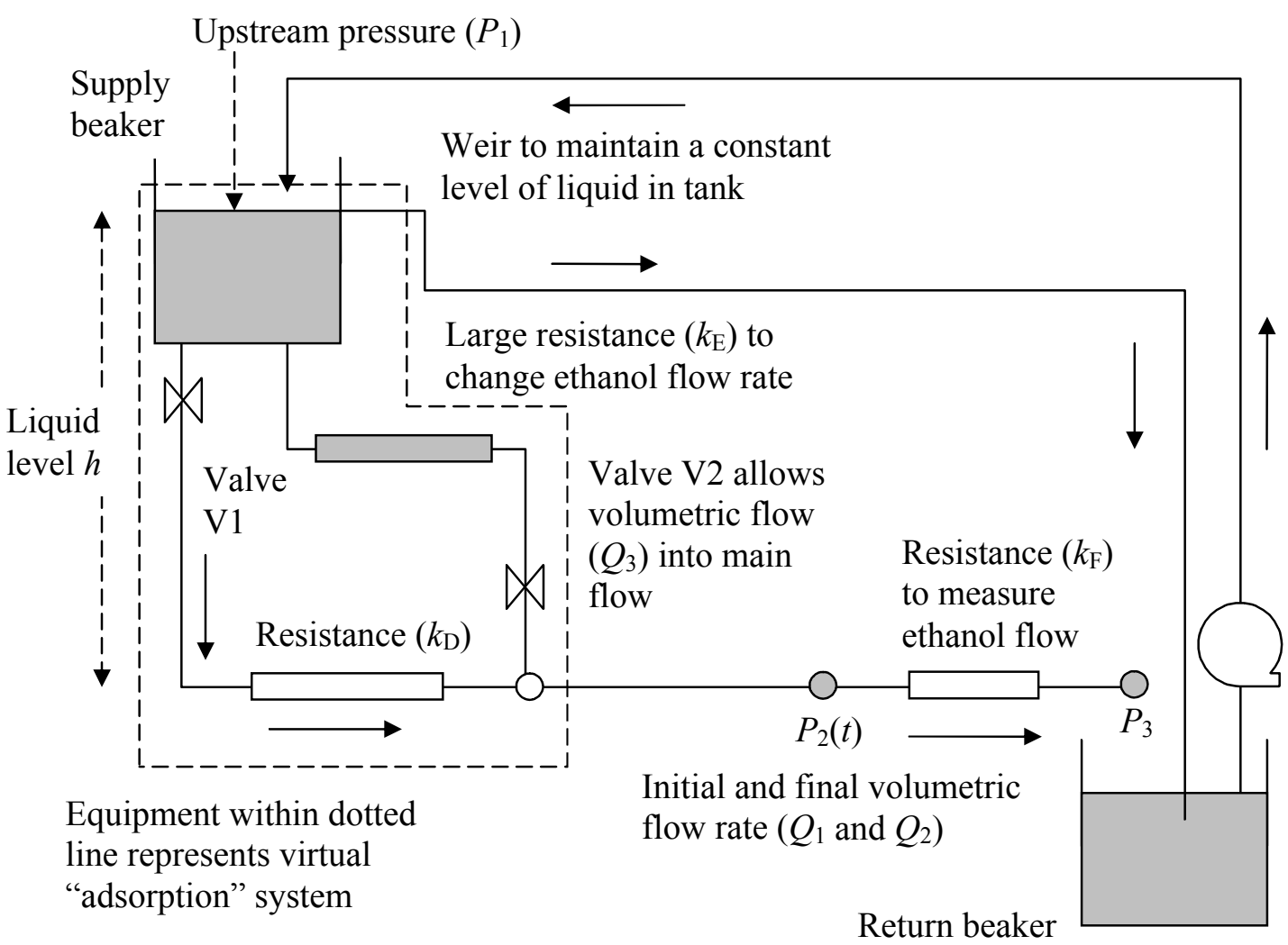

Figure 5: Schematic of actual experimental arrangement to assess the sensitivity of a gravityfed system for the detection of changes in flow rate. 


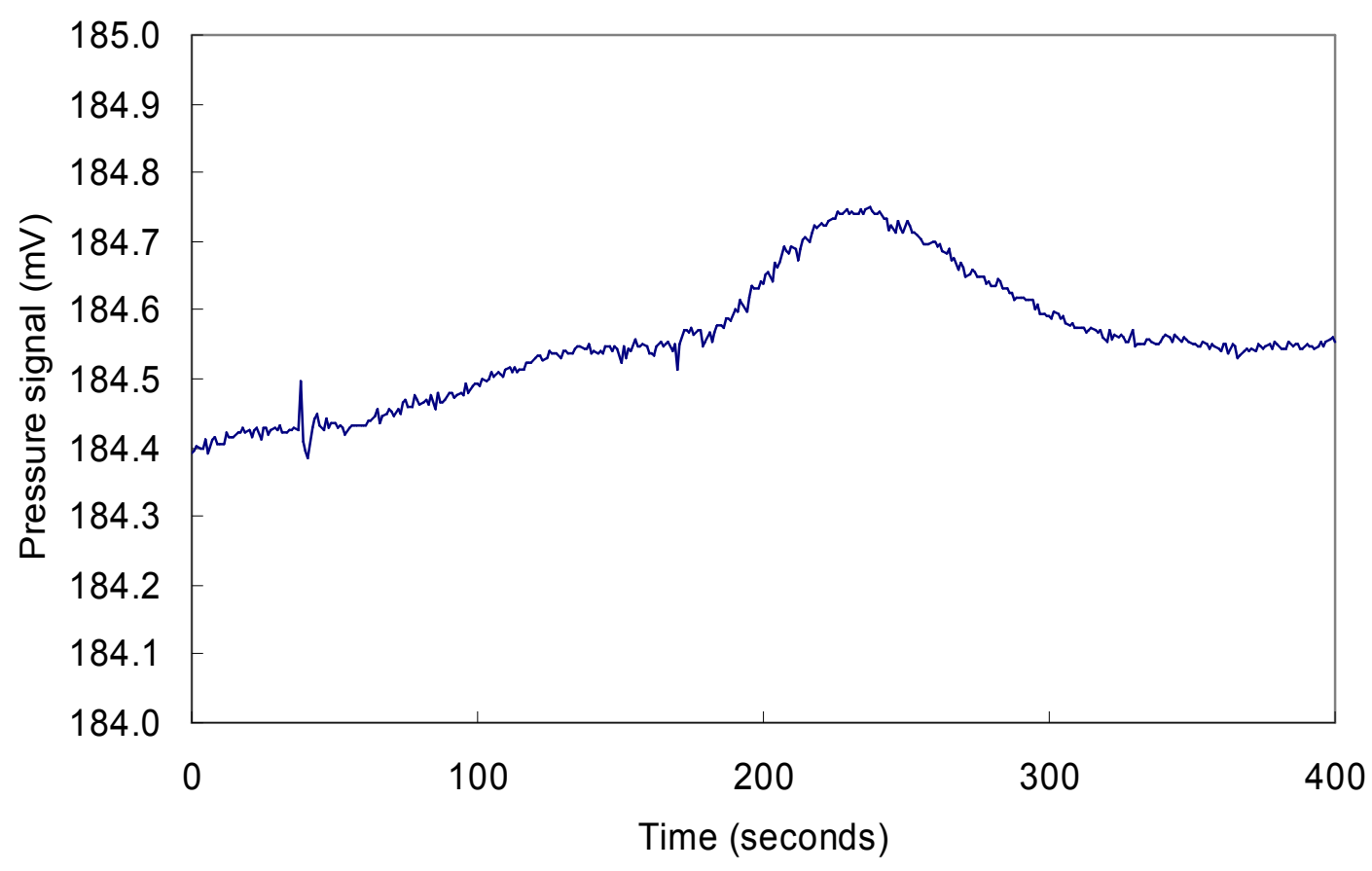

Figure 6: Baseline signal (variation in $P_{2}$ ) over 400 seconds, for which it can be seen that the voltage stays within a range of about $0.3 \mathrm{mV}$. The flow rate of ethanol through resistance $\mathrm{C}$ is about $1 \mathrm{~mL} / \mathrm{min}$. The $1 \mathrm{mV}$ span corresponds to $0.0028 \mathrm{mbar}$. 


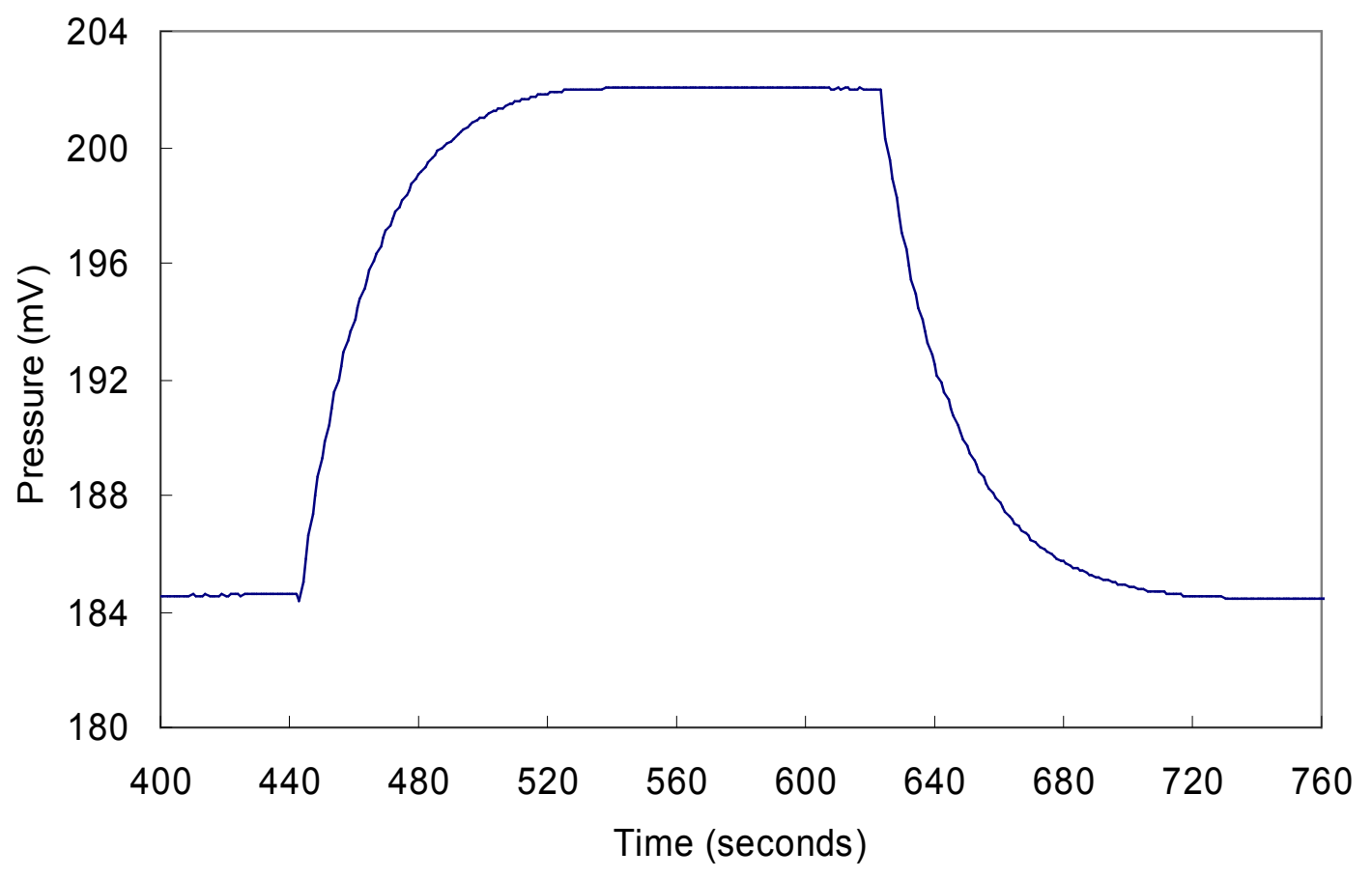

Figure 7: The first step in the pressure $\left(P_{2}\right)$ signal is obtained by increasing the ethanol flow rate through the measurement resistance $\left(k_{\mathrm{C}}\right)$ by about $15 \%$, from an original value of 1 $\mathrm{mL} / \mathrm{min}$. The second step is obtained by reducing the ethanol flow to the original value. 